CT scan, and angiography if any involvement of the vessels is suspected.

Stable closed reduction of a posterior sternoclavicular dislocation can be done successfully using the method described in our case. A towel clip to grip the clavicle medially has been found to be helpful. Open reduction may be necessary with repair or fixation by one of various methods described. ${ }^{27}$ Transfixion with $\mathrm{K}$ wires is not recommended because of the risk of migration and potential damage to vital organs. ${ }^{1}$ Resection of the medial part of the clavicle may be the best choice, especially in cases discovered late. A figure of eight bandage for six weeks is sufficient for after care.

Although posterior sternoclavicular dislocations are rare, the potential serious com- plications makes early diagnosis and treatment important.

1 Gangahar D, Flogaites T. Retrosternal dislocation of the clavicle producing thoracic outlet syndrome. F Trauma 1978;18:369-72.

2 Lewonowski K, Bassett GS. Complete posterior sternoclavicular epiphyseal separation. Clin Orthop 1992;281: 84-8.

3 Gazak S, Davidson SJ. Posterior sternoclavicular dislocations: two case reports. $\mathcal{F}$ Trauma 1984;24:80-2.

4 Paterson D. Retrosternal dislocation of the clavicle. $\mathcal{f}$ Bone foint Surg 1961;43:90-4.

5 Leighton RK, Buhr AJ. Posterior sternoclavicular dislocations. Can f Surg 1986;29:104-6.

6 Wehner. Zur Konservation behandlung der Retrosternale Luxation der Klavikular Luxation. F Ortho Chir 1931;55: 409.

7 Worman LW, Leagus C. Intrathoracic injury following retrosternal dislocation of the clavicle. $\mathcal{F}$ Trauma 1967;7: retrosternal

8 Greelee DP. Posterior dislocation of the sternal end of the clavicle. $\mathcal{f}$ Am Med 1944; June:426-8.

\title{
Complete avulsion of the hamstring tendons from the ischial tuberosity. A report of two cases sustained in judo
}

\author{
Hideki Kurosawa, Ken Nakasita, Hiroyasu Nakasita, Shigeru Sasaki, Seigou Takeda
}

\begin{abstract}
Rupture of the hamstring tendon is a rare injury. Two cases of complete rupture of the hamstring tendons sustained while playing judo are reported. The diagnosis of a rupture of the hamstring tendons was difficult from physical examination because of severe pain on knee or hip joint movement. Magnetic resonance imaging was non-invasive and showed the lesion clearly. In one of these two cases the less satisfactory results of non-operative treatment were clearly shown in both isokinetic muscle force evaluation and sports activities.

(Br F Sports Med 1996;30:72-74)
\end{abstract}

Key terms: hamstring, avulsion, ischial tuberosity, judo.

Rupture of the hamstring tendon is a rare injury in sporting activities. ${ }^{1-3}$ We report two cases of complete rupture of the hamstring tendons sustained while playing judo. In neither case was a fracture of the ischial tuberosity identified on $x$ ray. One case was treated nonoperatively and the other operatively.

\section{Case report}

CASE 1

A 28 year old male, Judo 4 dan (fourth grade judo player), felt severe pain in the posterior side of the thigh of the pivoting leg when he was about to do the uchimata (inner thigh) move on his opponent during training (fig 1). It became impossible for him to stand on the leg and could not walk because of severe pain. He visited our outpatient clinic on the next day. On physical examination, no clearly palpable hollow indicating rupture of the hamstring tendons or muscles was discernible because of marked swelling and widespread subcutaneous bleeding; there was severe tenderness and pain on motion of the hip or knee joint. Magnetic resonance imaging (MRI) evaluation revealed a complete rupture of hamstring tendon from the ischial tuberosity (fig 2 , upper row).

$\mathrm{He}$ refused operative treatment and was immobilised in a single spica cast with the hip joint in neutral and the knee joint at about 60 degrees of flexion for three weeks. A partial weight bearing gait was then started. A range of motion exercises for the joints and stretching exercises of the muscles was begun as the pain lessened. Strengthening exercises were also introduced as for a strain of the hamstring. ${ }^{4} \mathrm{He}$ could walk with full weight bearing six weeks after the injury without support. Ten weeks after the injury, he resumed his training in judo.

MRI findings seven years after the injury showed that the ruptured end of the hamstring muscles remained within the soft tissues separate from the ischial tuberosity (fig 2, lower row). In the evaluation of muscle function at this time (Myoret, Kawasaki Jukoh Co), isokinetic hamstring strength on the injured side was $20-40 \%$ less than on the non-injured side, while the quadriceps power was equal on both sides. 


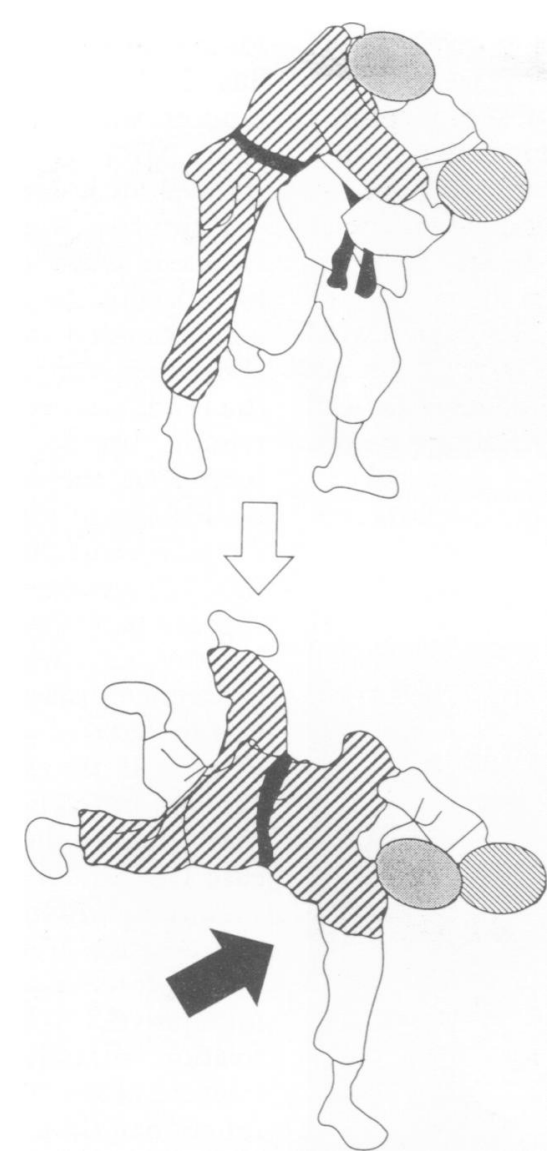

Figure 1 Case 1. Sudden knee extension of the pivoting leg with hip flexed while doing the uchimata move caused rupture of the hamstring tendon.
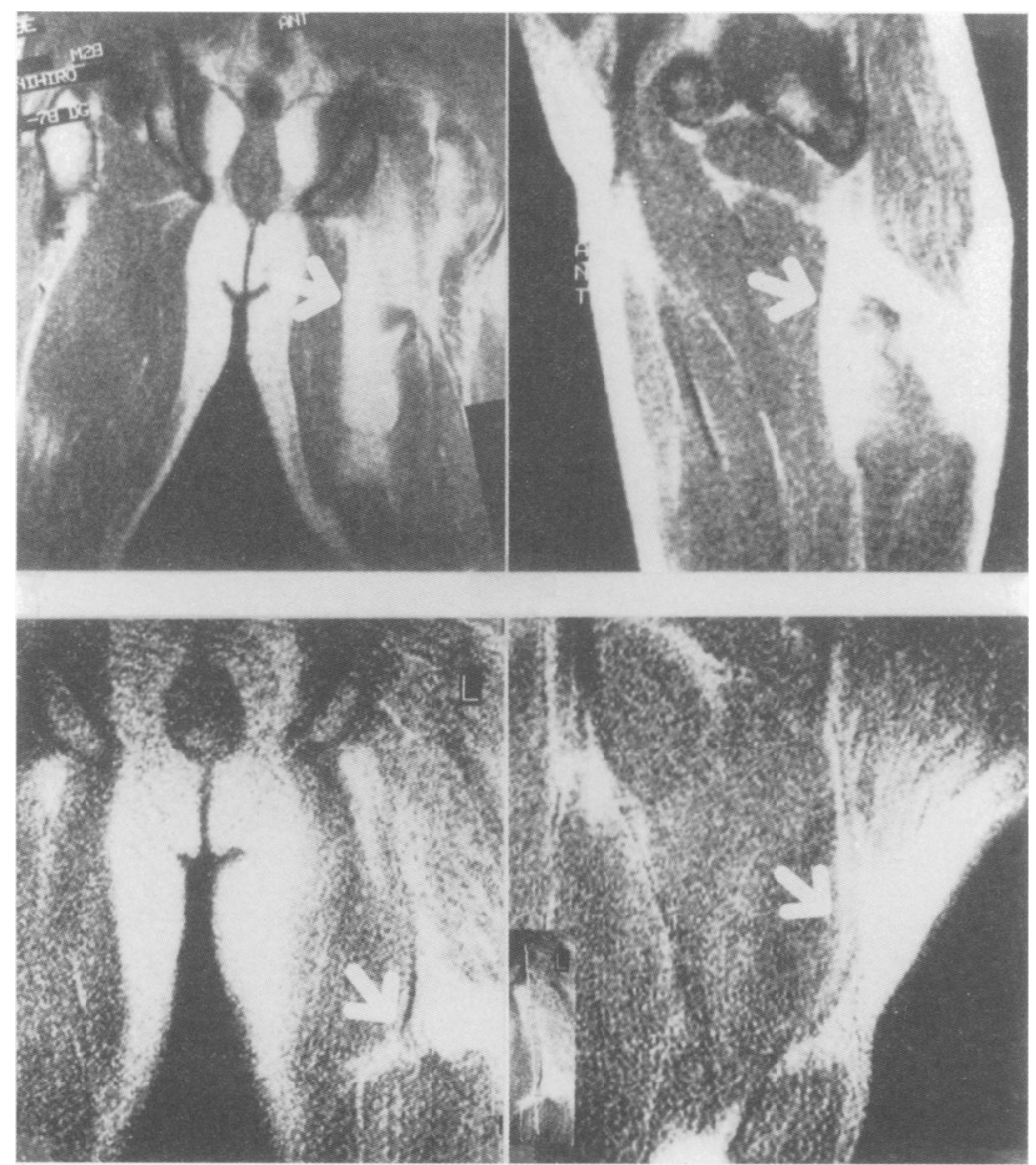

Figure 2 Magnetic resonance imaging of case 1: left row, frontal plane; right row, sagittal plane. Upper: soon after injury; lower: seven years after injury. Arrows indicate ruptured tendons.

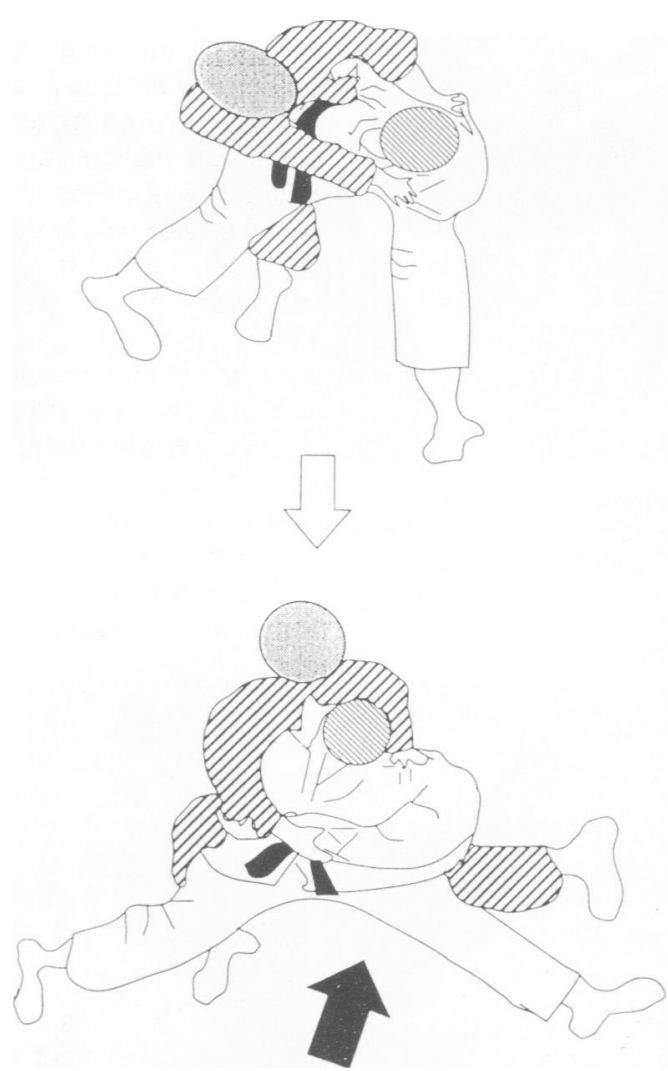

Figure 3 Case 2. Forceful hip flexion and abduction with knee fully extended avulsed the hamstring origin.

$\mathrm{He}$ is still a competitive judo player, but complains of occasional cramps in the posterior of the thigh while dashing, jumping, or on long distance running.

CASE 2

A 25 year old male, Judo 2 dan (second grade judo player), injured his pivoting leg when he did taiotoshi (valley fall) move but was overturned by his opponent (fig 3). A few hours after the accident, he appeared in our hospital, standing on one leg with the other knee flexed at about 40 degrees. He complained of severe pain and tenderness which increased with knee straightening or hip flexion. MRI revealed a complete rupture of the hamstring tendons (fig 4).

Four days after the injury, an operation was carried out. The three ruptured muscle tendons which were avulsed and had been transposed about $7 \mathrm{~cm}$ from the ischial tuberosity (fig 5) were restored to the periosteum of the ischial tuberosity by non-absorbable string with mattress sutures. Good stability of the sutured site was confirmed by moving the hip and knee joint to full flexion and extension. During this operation the short head of the biceps femoris was not identified. In the postoperative period, he was immobilised in a plaster cast, and then started a programme of muscle exercises similar to case 1 , since we were concerned that there might be re-rupture of the tendon if forceful contraction of the hamstring muscles was initiated too soon. The postoperative treatment proceeded smoothly with less pain than in case 1 . 


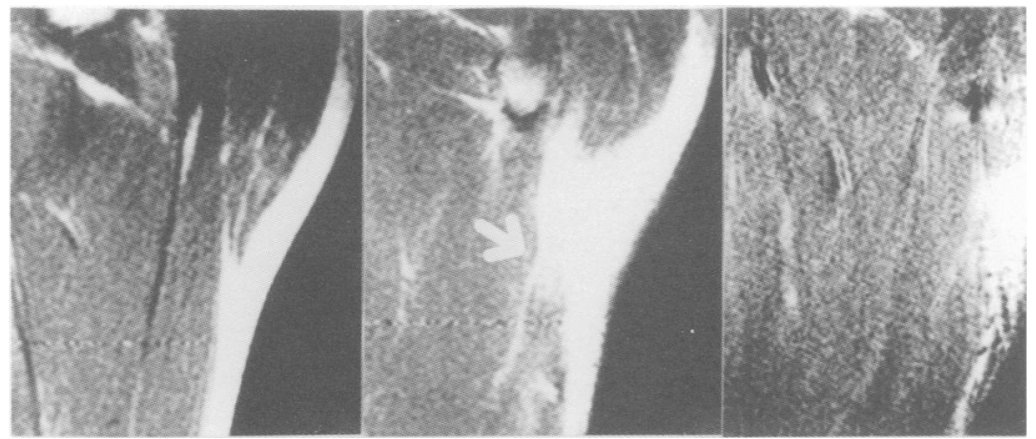

Figure 4 Magnetic resonance imaging (sagittal plane) of case 2: left, uninjured side; middle, soon after the injury; right: three weeks after operation. The arrow indicates the ruptured tendons.

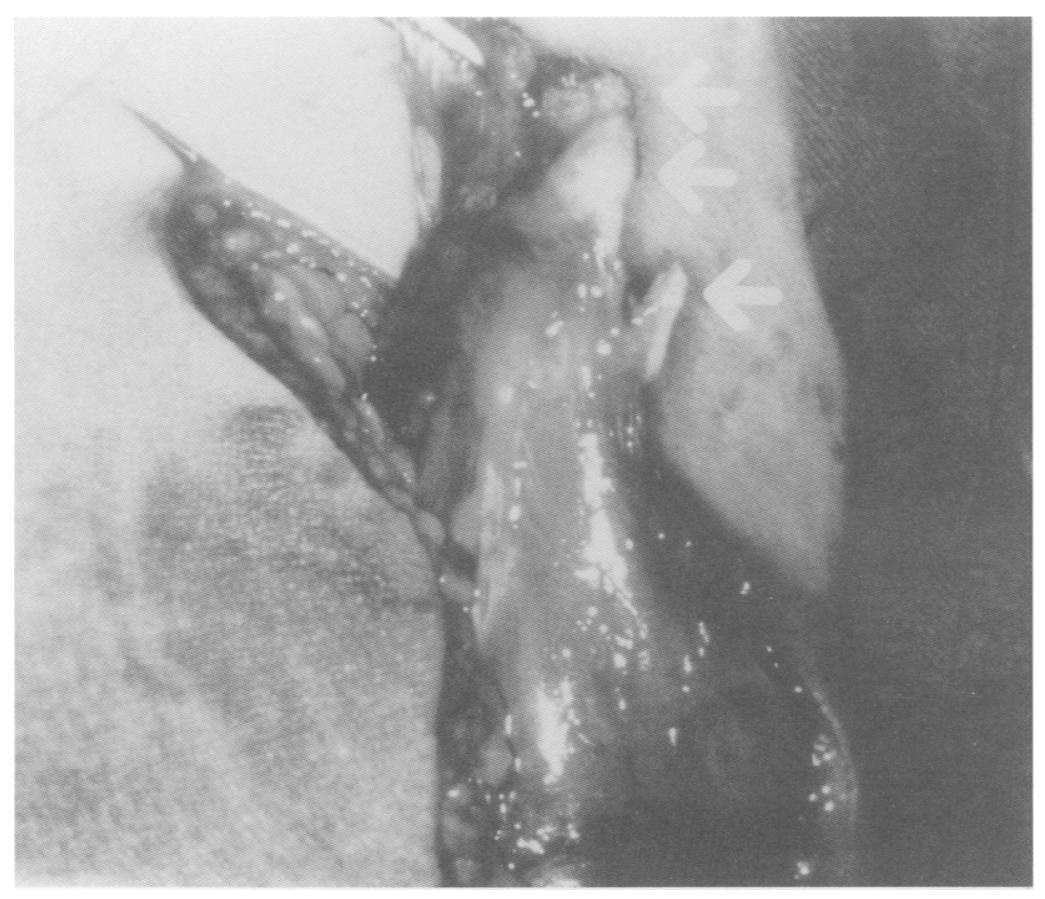

Figure 5 Avulsed hamstring tendons (arrows) at operation.

Isokinetic evaluation seven months after the operation showed that strength of the injured hamstring was about $80 \%$ of the non-injured side, while strength of the quadriceps was nearly the same on the two sides. By 12 months after the operation, strength of both quadriceps and hamstring muscles was nearly the same on the two sides. There is no difficulty with any sporting activities.

\section{Discussion}

The diagnosis of a rupture of the hamstring tendons was difficult by physical examination, while MRI was non-invasive and its findings showed the lesion clearly.

Rupture of the hamstring tendon is reported to occur when abduction of the hip joint is forced with the hip joint flexed and the knee joint extended as in case $2 .^{23}$ But, as in case 1 , active hamstring muscle forces can also rupture the tendon, as is usually the case with Achilles tendon rupture. In neither of our cases was a biopsy of the muscle done, but there was no history of disease predisposing to muscle damage or of consumption of unusual drugs. In an experimental cadaveric study, tendon rupture was shown to occur even in normal healthy muscles and tendons. ${ }^{5}$ In another cadaveric muscle analysis, the hamstring muscle was shown to contain a relatively large number of type II fibres, which produce rapid force generation. ${ }^{6}$ The results from these studies may support the mechanism of the injury in case 1 .

Although Achilles tendon rupture heals with conservative treatment, ${ }^{7}$ operative treatment for rupture of the hamstring tendons seems imperative. It is stated that open reduction and fixation should be carried out in avulsion fracture of the ischial epiphysis because of the functional disability which persists over the years. ${ }^{8}$ In our two cases, the less satisfactory results of conservative treatment were clearly demonstrated both in isokinetic muscle force evaluation and in sports activities.

1 Anzel SH Covey KW Weiner AD, et al. Disruption of muscles and tendons. An analysis of 1,014 cases. Surgery 1959;45:406-14

2 Blasier RB, Morawa LG. Complete rupture of the hamstring origin from a water skiing injury. Am $\mathcal{f}$ Sports Med 1990;18:435-7.

3 Ishikawa K, Kai K, Mizuta $\mathrm{H}$. Avulsion of the hamstring muscles from the ischial tuberosity. A report of two cases. Clin Orthop 1987;232:153-5.

4 Agre JC. Hamstring injuries. Proposed aetiological factors, prevention, and treatment. Sports Med 1985;2:21-33.

5 McMaster PE. Tendon and muscle ruptures. Clinical and experimental studies on the cases and location of subcutaneous ruptures. F Bone foint Surg 1933;15: subcutan 22 .

6 Garret WE, Califf JC, Bassett FH. Histochemical correlates of hamstring injuries. Am $\mathcal{f}$ Sports Med 1984;12: 98-103.

7 Nisor L. Surgical and non-surgical treatment of Achilles tendon rupture. $\mathcal{F}$ Bone foint Surg $[\mathrm{Am}]$ 1981;63A: 394-9.

8 Schlonsky J, Olix ML. Functional disability following avulsion fracture of the ischial epiphysis. Report of two cases. F Bone foint Surg [Br] 1972;54A:641-4. 